\title{
The Stability of a Modified Form of Reaction Diffusion Equation in Phase Plane
}

\author{
Esen Hanaç ${ }^{1^{*}}$ \\ 1*Adiyaman University, Faculty of Arts and Sciences, Departmant of Mathematics, Adıyaman, Turkey, (ORCID: 0000-0001-5561-7495), ehanac@adiyaman.edu.tr
}

(First received 19 April 2021 and in final form 24 July 2021)

(DOI: $10.31590 /$ ejosat.920615)

ATIF/REFERENCE: Esen Hanaç. (2021). The Stability of a Modified Form of Reaction Diffusion Equation in Phase Plane. European Journal of Science and Technology, (21). 702-706.

\begin{abstract}
We examine the dynamics of nonlinear system related in the following equation namely,

$u_{t}+u u_{x}=u_{x x}-\left(1-u^{2}\right)$

where $x \neq 0$, represents distance, $t$ represents time. As a beginning we start to get ordinary differential equation form of above equation after substituting of a new transformation into it. Then dynamical system of ordinary differential equation form is indicated depend on selected variables. According to the critical points of the dynamical system of ordinary differential equation form, the structures of the eigenvalues of them are identified. We attempt to find a heteroclinic connection from unstable node to stable node in parallel with travelling wave solutions for the minimum wave speed and the structure of the other travelling wave solutions to be identified. Furthermore, by applying a matlab implementation of ode45 package the ordinary differential equation form is numerically solved in phase plane and applying parabolic method to compare analytic and numric results.
\end{abstract}

Keywords: Phase plane analysis, stable node, unstable node.

\section{Modife Formdaki Reaksiyon Difüzyon Denkleminin Faz Diyagramındaki Kararlılığı}

$\ddot{O} z$

Aşağıdaki denklem

$u_{t}+u u_{x}=u_{x x}-\left(1-u^{2}\right)$

$x \neq 0$, uzaklığı ve $t$ zamanı niteleyen, nonlineer dinamik sistemi içerisinde incelenmiştir. Başlangıç olarak yukarıdaki denleme yeni dönüşüm uygulanarak kısmi differansiyel formu elde edildi. Sonra oluşturulan denklemin seçilmiş değerlerine bağlı kalınarak kısmi diferansiyel denklemin dinamik sistemi tanımlandı. Oluşturan kısmi diferansiyel formdaki denklemin dinamik sisteminin kritik noktalarına bağlı kalınarak, sistemin özdğerlerinin yapısı tanımlandı. Amacımız unstable node dan stale node a dğoru bir heteroclinic yapı tanımlamak ve buna bağlı olarak dalgalanma hareketleri için gereken en küçük dalga hızını tanımlayıp başka dalgalanma hareketleri oluşumu varsa yapılarını belirlemek. Son olarak yapılan uygulamalara ek olarak matlab ode45 paketi kısmi diferansiyel formdaki denkleme uygulanarak faz diyagramında numerik çözümü elde edilmiştir ve parabolic method uygulanarak elde edilen numerik çözümlerle analitik çözüm karşılaştırılmıştır.

Anahtar Kelimeler: Faz diyagram analizi, stable node, unstable node.

\footnotetext{
*Corresponding Author: ehanac@adiyaman.edu.tr
} 


\section{Introduction}

It is well known that obtaining analytical solutions of nonlinear partial differential equations has a significant role to define physical phenomena which are rising in several areas such as physics, biology, chemistry and engineering. Many different methods have been applied to determine the analytical wave solutions to nonlinear equations for many years. Numerous nonlinear equations have an extensive area of applications in fluid mechanics, chemical and plasma physics and so on. One of those equations is the generalized Burgers-Fisher equation,

$$
u_{t}+\delta u^{n} u_{x}=\varepsilon u_{x x}+\vartheta u\left(1-u^{n}\right)
$$

where $\delta, \varepsilon, \vartheta$ in real number and $n>0$ is constant. Some analytic accurate travelling wave solutions of the equation (1) have been demonstrated by applying different methods. When $\delta$ is counted as 0 the equation (1) is reduced to the Fisher-KPP equation which has been studied by many authors. When $\vartheta$ is counted as 0 the equation (1) is reduced to the generalized Burgers equation. Many scientists in different area have given an enormous effort to the generalized Burgers equation to find the exact travelling wave solutions of it through the years due to its value in science. Despite of the methods used in those equations to solve travelling wave solutions of them the dynamical attitude of the ordinary differential equation forms of the equation (1) or reduced forms of (1) have not been taken as consideration. In this paper, the dynamic system of a modified form of the equation (1) given as

$$
u_{t}+u u_{x}=u_{x x}-\left(1-u^{2}\right),
$$

where $x \neq 0$, represents distance, $t$ represents time, has been considered.

\section{Dynamic System}

In this section we consider the equation in the following namely

$$
u_{t}+u u_{x}=u_{x x}-\left(1-u^{2}\right)
$$

and substituting the new coordinate $U(z)=x-c t$, where $c$ is a wave speed, into the equation (2), we obtain the ode form of the equation (2),

$$
-c U^{\prime}+U U^{\prime}=U^{\prime \prime}-\left(1-U^{2}\right) .
$$

Letting $U^{\prime}=B$ then we get the dynamic system of the equation (3) that

$$
\begin{aligned}
& U^{\prime}=B \\
& B^{\prime}=-c B+U B+\left(1-U^{2}\right) .
\end{aligned}
$$

$$
J(U, B)=\left[\begin{array}{cc}
0 & 1 \\
B-2 U & U-C
\end{array}\right] .
$$

According to the Linearization Theorem we sort out the structure of the fix points. If the eigenvalues of the fix point are both less than 0 then the structure of the fix point will be named stable node. If the eigenvalues of the fix point are both positive then the structure of the fix point will be named unstable node. If the eigenvalues of the fix point have different signs then the structure of the fix point will be named saddle point. We now consider the point $(1,0)$ then we have the jacobian matrix the point $(1,0)$ just like that

$$
J(1,0)=\left[\begin{array}{cc}
0 & 1 \\
-2 & 1-c
\end{array}\right]
$$

Eigenvalues of the matrix $J(1,0)$ are given

$$
\alpha_{ \pm}=\frac{(1-c) \pm \sqrt{(1-c)^{2}-8}}{2}
$$

when $(1-c) \geq \pm 2 \sqrt{2}$ that gives $c \geq 1+2 \sqrt{2}$ and $c \leq 1-$ $2 \sqrt{2}$. So the behavior of the point $(1,0)$ is unstable node when $c \leq 1-2 \sqrt{2}$ and the behavior of the point $(1,0)$ is stable when $c \geq 1+2 \sqrt{2}$. Secondly, we consider the point $(-1,0)$ then we have that

$$
J(-1,0)=\left[\begin{array}{cc}
0 & 1 \\
2 & -1-c
\end{array}\right] .
$$

Eigenvalues of the matrix $J(-1,0)$ are given

$$
g_{ \pm}=\frac{(1+c) \pm \sqrt{(1+c)^{2}+8}}{2}
$$

and $g_{+}>0>g_{-}$the point $(-1,0)$ is saddle node. We finally define the structure of the equilibrium points $(1,0))$ and $(-1,0)$ ) by using linearization theorem. We further note that from unstable point to saddle point there is a heteroclinic connection between them.

\subsubsection{Phase portrait of equilibirum points}

In this subsection we demonstrate the phase potraits of the equilibrum points of dynamic system (4) individually by applying matlab generated implementation. We exhibit phase portraits in Figure 1, 2 and 3 for various values of $c$.

The dynamic system (4) has two fix points those are $(1,0)$ and (1,0). Firstly we indicate the jacobian matrix of the system (4) 


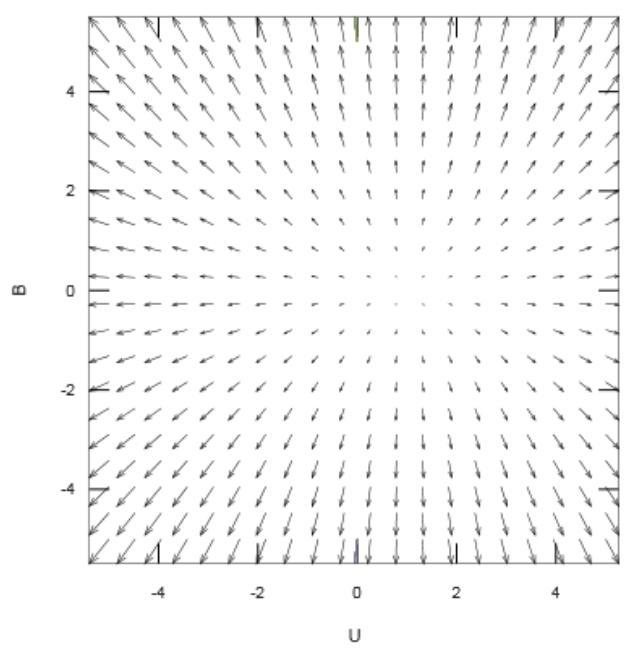

Figure 1: Phase portrait of $(U, B)$ in the locality of the equilibrium point $(1,0)$ when $\mathrm{c} \leq 1-2 \sqrt{2}$. It is clear to observe all arrows diverge from the equilibrium point.



Figure 2: Phase portrait of $(U, B)$ in the locality of the equilibrium point $(1,0)$ when $c \geq 1+2 \sqrt{2}$. It is clear to observe all arrows approach to the equilibrium point with red solid line

In Figure 4, trajectories of the system (4) are featured in the phase space portrait for a variety of $c \geq 1+2 \sqrt{2}$ in times by using matlab ode45 package implemantation. We notice from the Figure 4 that while $c \geq 1+2 \sqrt{2}$ all paths in the phase space connecting from $(-1,0)$ to $(1,0)$ as time $t$ in $[0,50]$, Additionally, we consider exact solution of the equation (2) when $c=1+$ $2 \sqrt{2}$ and after some minor calculations equation (2) reduces to Bernoulli's equation namely

$$
U^{\prime}=-c U+\frac{U^{2}}{2} \text {. }
$$

We obtain the solution of equation (5) is given by

$$
U(z)=1-\frac{2}{1+A e^{-(1+2 \sqrt{2}) z}}
$$

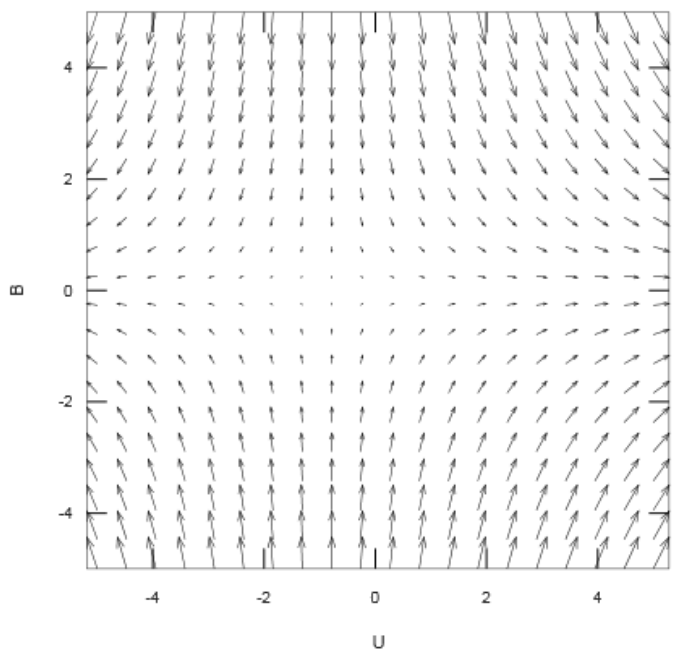

Figure 3: Phase portrait of $(U, B)$ in the locality of the equilibrium point $(-1,0)$ for all value of $\mathrm{c}$. It is clear the graph establishs saddle node.

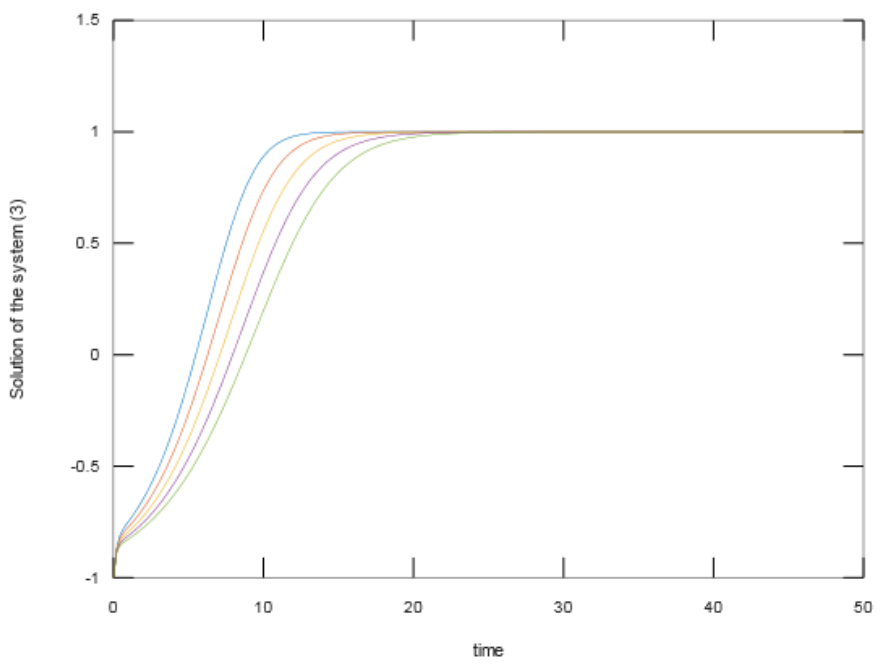

Figure 4:Trajectories of the system (4) for dissimilar value of $c \geq 1+2 \sqrt{2}$. Each paths symbolise the trajectory for variety of speed c like, 4, 4.5, 5, 5.5, and 6 respectively.

$$
U(z) \sim\left\{\begin{array}{l}
\sim 1-\frac{1}{A} e^{(1+2 \sqrt{2}) z} z \rightarrow-\infty \\
\sim A e^{-(1+2 \sqrt{2}) z}-1 z \rightarrow \infty
\end{array}\right.
$$

where $A$ is constant. Therefore we observe $U(z) \rightarrow 1$ while $z \rightarrow-\infty$ and $U(z) \rightarrow-1$ while $z \rightarrow \infty$. The results of the system (6) are the key for supporting heteroclinic orbit connects from the saddle point $(-1,0)$ to the point $(1,0)$ when $c \geq 1+2 \sqrt{2}$. Heteroclinic orbit represents to waves. Thence, it supports that the equation (2) in examined phase plane displays soliton namely 


\section{Numerical Simulations}

In this section we compare exact solution (6) with the numerical solutions of the equation (2). In order to obtain the numeric results of the equation (2) we use a numeric formul namely, parabolic method for the details of the numeric method the references (Griffiths and Schiesser, 2009; Griffiths and Schiesser, 2010; Landejuela, 2011) is referred to read for who is interested in. After some calculations we have modified form of equation like,

$$
\begin{aligned}
U_{j}^{n+1}= & U_{j}^{n}+\Delta t\left(\frac{U_{j+1}^{n}-2 U_{j}^{n}+U_{j-1}^{n}}{\Delta x^{2}}\right) \\
& +\frac{U_{j-\frac{1}{2}}^{n}-U_{j+1 / 2}^{n}}{\Delta x}+M_{j}^{n}(x)-1=0
\end{aligned}
$$

where $M_{j}^{n}(x)$ refers to as $u^{2}(x)$. We represent the numerical solution of the equation (1) with chosing NN grid point equals to $200, \Delta t=.5$ and the exact solution (6) which is obtained in the subsection 2.1.1 in the case when $c=1+2 \sqrt{2}$. In Figure 5 the $\mathrm{sS}$ of the equation(2) with wave speed $c=1+2 \sqrt{2}$ is observed to grow quickly as $t \rightarrow \infty$ and the green dashed line is represented by the exact solution and the overlap one that purple line is represented by the numeric result, affirms that time dependant solution gets close to the exact solution moderately quick. We also present the numerical solution of the equation (2) with chosing NN grid point equals to $200, \Delta t=.5$ and the exact solution (6) which is obtained in the subsection 2.1.1 in the case when $c=1-2 \sqrt{2}$. The sketch in Figure 7 is withdrawing sS for the equation (1). Moreover Figure 7 exposes intensly good agreement between exact solution in green dashed line and numeric result in purple line at $\mathrm{t}=6$.

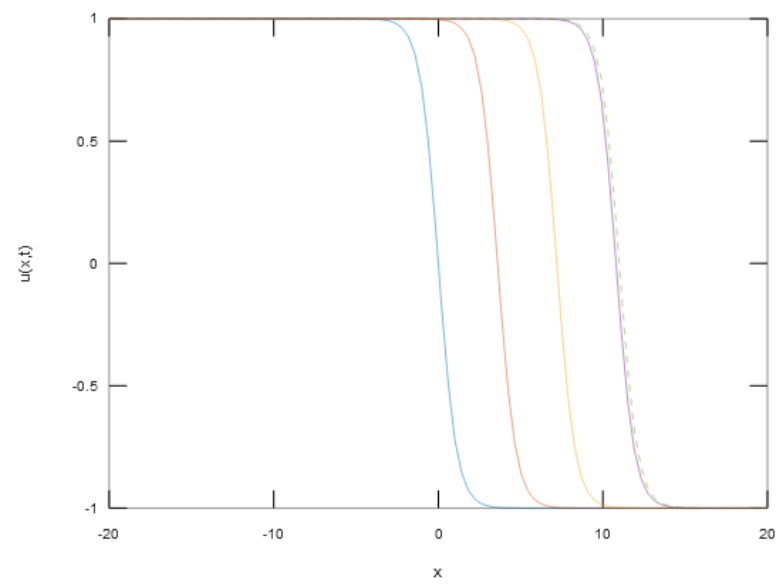

Figure

5: Graph of exact solution (green dashed line) and the numerical solutions of the equation (2) at times $t=0,2,4,6$.

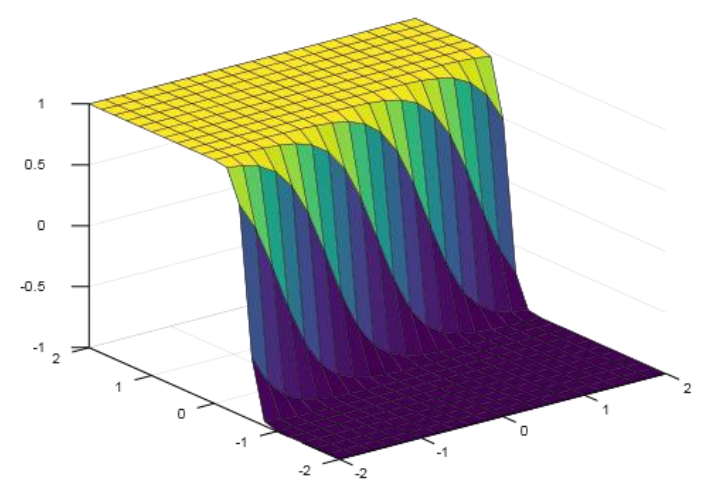

Figure 6: Soliton solutions of the equation (2) while wave speed $c=1+2 \sqrt{2}$.



Figure 7: Graph of exact solution (green dashed line) and the numerical solutions of the equation (2) at times $t=0,2,4,6$.

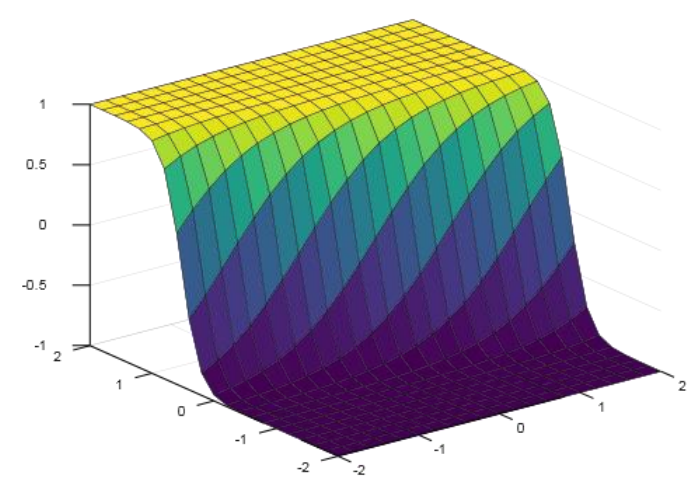

Figure 8: Regressive Soliton solutions of the equation (2) while wave speed $c=1-2 \sqrt{2}$.

Results in Figure 6 and Figure 8 verify the solutions as sS and regressive sS same in Figures 5 and 7.

\section{Conclusion}

In this paper, we conceive the modified form equation (2) in dynamic theory. We peruse the dynamic behaviour of soliton solutions of the equation (2) applying linearizaton theorem. We 
attain phase profiles and indicate heteroclinic orbit occurance which provides soliton solutions. Lastly, we apply parabolic method to get numerical solutions of the equation (2) and compare with exact solution in same distance $\mathrm{x}$ with time intervals for wave speed $c=1+2 \sqrt{2}, \quad c=1-2 \sqrt{2}$ respectively. The modified form equation has various impressive properties. The modified form mathematical model has soliton solutions for $c=1+2 \sqrt{2}$. Mathematical model of the modified form ensures a simple phsical version, which is named as regressive soliton solutions, for an exact solution with $c=1-$ $2 \sqrt{2}$, despite the travelling wave solutions with $c<2$ on the pretense of unpyhsical (Canosa, 1973; Edelstein-Keshet, 2005; Fisher, 1937; Kolmogorov et al, 1937; Kot, 2003; Murray, 2002 ).

\section{References}

Behzadi, S.S and Araghi, M.A.F., (2011).Numerical Solution for Solving Burgers-Fisher Eguation by Using Iterative Methods.Mathematical and Computational Applications16, 443-455. https://doi.org/10.3390/mca16020443

Bramson, M.D., (1983). Convergence of solutions of the Kolmogorov equation to travellingwaves. Mem. Amer. Math. Soc. 44

Burgers, J.M., (1939). Mathematical examples illustrating relations occurring in the theoryof turbulent fluid motion.Verh. Nederl. Akad. Wetensch. Afd. Natuurk.17, 153.

Burgers, J.M., (1940). Application of a model system to illustrate some points of the statistical theory of free turbulence.Proc. Kon. Nederl. Akad. Wetensch.43, 2-12.

Burgers, J.M., (1975). The Nonlinear Diffusion Equation. D. Reidel Publishing Company,Dordrecht, Holland.

Canosa, J., (1973). On a nonlinear diffusion equation describing population growth. IBM Journal of Research and Development. 17 307-313. https://doi.org/10.1147/rd.174.0307

Edelstein-Keshet, L., (2005). Mathematical Models in Biology. SIAM,

Philadelphia. https://doi.org/10.1137/1.9780898719147

Fisher, RA., (1937). The wave of advance of advantageous genes. Annals of Eugenics. 7 355-369. https://doi.org/10.1111/j.1469-1809.1937.tb02153.x

Griffiths, G., Schiesser, W. E., (2009). A Compendium of Partial Differential EquationModels. Cambridge University Press doi:10.1017/CBO9780511576270

Griffiths, G., Schiesser, W. E., (2010). Travelling Wave Analysis of Partial DifferentialEquations. Academic Press. ISBN: 978-0-12-384652-5

Kolmogorov, AN, Petrovskii, PG, Piskunov, NS. (1937). A study of the diffusion equation with increase in the amount of substance, and its application to a biological problem. Moscow

University Mathematics Bulletin. 1 1-26.

Kot, M., (2003). Elements of Mathematical Ecology. Camridge University Press, Cambridge. https://doi.org/10.1017/CBO9780511608520

Landejuela, M., (2011). Burgers Equation. BCAM Internship report: Basque Center forApplied Mathematics.

McKean, H.P., (1975) . Application of Brownian motion to the equation of Kolmogorov-Petrovskii-Piskunov.Comm. Pure Appl. Math.28, 323-331.
Murray, JD. (2002). Mathematical Biology I: An Introduction. Third edition, Springer, New York.

Van Saarloos, W., (2003). Front propagation into unstable states.Phys. Rep.386, 29-222. 